New Drug Update

\title{
Apalutamide: a better option for the treatment of non-metastatic castration resistant prostatic carcinoma
}

\author{
Raushan Kumar Ranjan, Akash Chandra*
}

Department of Pharmacology, Indira Gandhi Institute of Medical Sciences, Patna, Bihar, India

Received: 28 June 2018

Accepted: 26 July 2018

*Correspondence to:

Dr. Akash Chandra,

Email: drakash1984@gmail.com

Copyright: (C) the author(s), publisher and licensee Medip Academy. This is an openaccess article distributed under the terms of the Creative Commons Attribution NonCommercial License, which permits unrestricted noncommercial use, distribution, and reproduction in any medium, provided the original work is properly cited.

\begin{abstract}
Prostate cancer is cancer of the prostate, a gland in the male reproductive system. Most prostate cancers are slow growing; however, some grow relatively quickly. The cancer cells may spread from the prostate to other area of the body, particularly the bones and lymph nodes. Factors that increase the risk of prostate cancer include older age, a family history of the disease, and race. About $99 \%$ of cases occur in males over the age of 50. Clinical features include hematuria, dysuria (painful urination), nocturia(urination at night). Lower blood levels of vitami D may increase the risk of developing prostate cancer. Infection with the sexually transmitted diseases, chlamydia, gonorrhea, syphilis and prostatitis seem to increase risk of prostate cancer. Diagnosis can be confirmed by digital rectal examination (DRE) with prostate-specific antigen (PSA) blood test, cystoscopy, transrectal ultrasonography and biopsy (The removal of small pieces of the prostate for microscopic examination). Medicines like 5-alpha-reductase inhibitors (finasteride and dutasteride) reduce the overall risk of prostate cancer. Apalutamide, sold under the brand name Erleada, is a nonsteroidal antiandrogen (NSAA) medication which is used in the treatment of prostate cancer. It is specifically indicated for use in conjunction with castration in the treatment of non-metastatic castration-resistant prostate cancer (NM-CRPC). It is taken by mouth. Apalutamide was first described in 2007 and was approved for the treatment of prostate cancer in February 2018. Apalutamide is used in conjunction with castration, either via bilateral orchiectomy or gonadotropinreleasing hormone analogue ( $\mathrm{GnRH}$ analogue) therapy, as a method of androgen deprivation therapy in the treatment of non-metastatic castration-resistant prostate cancer (NM-CRPC).
\end{abstract}

Keywords: Prostatitis, Nonsteroidal antiandrogen, Non-metastatic castrationresistant prostate cancer

\section{INTRODUCTION}

Most prostate cancers are slow growing; however, some grow relatively quickly. The cancer cells may spread from the prostate to other area of the body, particularly the bones and lymph nodes. It may initially cause no symptoms. In later stages, it can lead to difficulty urinating, blood in the urine or pain in the pelvis, back, or when urinating. Factors that increase the risk of prostate cancer include older age, a family history of the disease, and race. About $99 \%$ of cases occur in males over the age of 50. Having a first- degree relative with the disease increases the risk two to threefold. In the United States, it is more common in the African American population than the White American population. Other factors that may be involved include a diet high in processed meat, red meat or milk products or low in certain vegetables. Treatments may include a combination of surgery, radiation therapy, hormone therapy or chemotherapy. When it only occurs inside the prostate, it may be curable. In those in whom the disease has spread to the bones, pain medications, bisphosphonates and targeted therapy, among others, may be useful. Most people with prostate cancer do not end up 
dying from the disease. The 5-year survival rate in the United States is $99 \%$. Globally, it is the second most common type of cancer and the fifth leading cause of cancer-related death in men. In 2012, it occurred in 1.1 million men and caused 307,000 deaths. Studies of males who died from unrelated causes have found prostate cancer in $30 \%$ to $70 \%$ of those over age 60 . Early prostate cancer usually has no clear symptoms. Sometimes prostate cancer does cause symptoms, often similar to those of diseases such as benign prostatic hyperplasia. These include frequent urination, nocturia (increased urination at night), difficulty starting and maintaining a steady stream of urine, hematuria (blood in the urine), and dysuria (painful urination). A study based on the 1998 Patient Care Evaluation in the US found that about a third of patients diagnosed with prostate cancer had one or more such symptoms, while two-thirds had no symptoms. ${ }^{1}$ Prostate cancer is associated with urinary dysfunction as the prostate gland surrounds the prostatic urethra. Changes within the gland, therefore, directly affect urinary function. Because the vas deferens deposits seminal fluid into the prostatic urethra, and secretions from the prostate gland itself are included in semen content, prostate cancer may also cause problems with sexual function and performance, such as difficulty achieving erection or painful ejaculation. ${ }^{1}$ Metastatic prostate cancer that has spread to other parts of the body can cause additional symptoms. The most common symptom is bone pain, often in the vertebrae (bones of the spine), pelvis, or ribs. Spread of cancer into other bones such as the femur is usually to the proximal or nearby part of the bone. Prostate cancer in the spine can also compress the spinal cord, causing tingling, leg weakness and urinary and fecal incontinence. ${ }^{2}$ The primary risk factors are obesity, age, and family history. Prostate cancer is very uncommon in men younger than 45 but becomes more common with advancing age. The average age at the time of diagnosis is $70 .^{3}$ Most hormone dependent cancers become resistant to treatment after one to three years and resume growth despite hormone therapy. Previously considered "hormonerefractory prostate cancer" or "androgen-independent prostate cancer", the term castration-resistant has replaced "hormone refractory" because while they are no longer responsive to castration treatment (reduction of available androgen/testosterone by chemical or surgical means), these cancers still show reliance upon hormones for androgen receptor activation. ${ }^{4}$ The cancer chemotherapic docetaxel has been used as treatment for CRPC with a median survival benefit of 2 to 3 months. A second-line chemotherapy treatment is cabazitaxel. ${ }^{5}$ A combination of bevacizumab, docetaxel, thalidomide and prednisone appears effective in the treatment of Castration Resistant Prostatic Cancer. Apalutamide is another better choice for the treatment of castration resistant prostatic cancer.

\section{APLATUMIDE}

Apalutamide is a nonsteroidal antiandrogen (NSAA) medication which is used in the treatment of prostate cancer. It is specifically indicated for use in conjunction with castration in the treatment of non-metastatic castration-resistant prostate cancer (NM-CRPC). It is taken by mouth. Side effects of apalutamide when added to castration include fatigue, nausea, abdominal pain, diarrhea, high blood pressure, rash, Rarely, it can cause seizures. Apalutamide is an antiandrogen, and acts as an antagonist of the androgen receptor, the biological target of androgens like testosterone and dihydrotestosterone. In doing so, it prevents the effects of these hormones in the prostate gland and elsewhere in the body. Apalutamide was first described in 2007 and was approved for the treatment of prostate cancer in February 2018. It was the first medication to be approved specifically for the treatment of NM-CRPC. Apalutamide is used in conjunction with castration, either via bilateral orchiectomy or gonadotropin-releasing hormone analogue (GnRH analogue) therapy, as a method of androgen deprivation therapy in the treatment of NM-CRPC. It is also a promising potential treatment for metastatic castrationresistant prostate cancer (mCRPC), which the NSAA enzalutamide and the androgen synthesis inhibitor abiraterone acetate are used to treat. ${ }^{6}$ Apalutamide is provided in the form of $60 \mathrm{mg}$ oral tablets. It is taken at a dosage of $240 \mathrm{mg}$ once per day (four tablets) when used in the treatment of NM-CRPC. Aplatumide is contraindicated in pregnancy and persons who susceptible to seizures.

\section{PHARMACOLOGY}

\section{Pharmacodynamics}

Apalutamide acts as a selective competitive silent antagonist of the androgen receptor (AR) of the androgen receptor, via the ligand-binding domain, and hence is an antiandrogen. ${ }^{7}$ It is similar both structurally and pharmacologically to the second-generation NSAA[Nonsteroidal antiandrogen] enzalutamide, but shows some advantages, including higher antiandrogenic activity as well as several-fold reduced central nervous system distribution. $^{7}$ The latter difference may reduce its comparative risk of seizures and other central side effects. ${ }^{7}$ Apalutamide has 5- to 10-fold greater affinity for the AR than bicalutamide, a first-generation NSAA. ${ }^{7}$ The acquired F876L mutation of the AR identified in advanced prostate cancer cells has been found to confer resistance to both enzalutamide and apalutamide. ${ }^{8} \mathrm{~A}$ newer NSAA, darolutamide, is not affected by this mutation, nor has it been found to be affected by any other tested/well-known AR mutations. ${ }^{9}$

\section{Other activities}

Apalutamide shows potent induction potential of cytochrome P450 enzymes similarly to enzalutamide. ${ }^{10} \mathrm{It}$ is a strong inducer of CYP3A4 and CYP2C19 and a weak inducer of CYP2C9, as well as an inducer of UDPglucuronosyltransferase. In addition, apalutamide is an inducer of P-glycoprotein, ABCG2, and OATP1B1.Apalutamide binds weakly to and inhibits the 
$\mathrm{GABA}_{\mathrm{A}}$ receptor in vitro similarly to enzalutamide $\left(\mathrm{IC}_{50}=\right.$ 3.0 and $2.7 \mu \mathrm{M}$, respectively) but due to its relatively lower central concentrations, may have a lower risk of seizures in comparison. ${ }^{11,12}$ Apalutamide has been found to significantly and concentration-dependently increase QT interval.

\section{Pharmacokinetics}

The oral bioavailability of apalutamide is $100 \%$. Mean peak levels of apalutamide occur 2 hours following administration, with a range of 1 to 5 hours. Food delays the median time to peak levels of apalutamide by approximately 2 hours, with no significant changes in the peak levels themselves or in area-under-curve levels. Steady-state levels of apalutamide are achieved following 4 weeks of administration, with an approximate 5-fold accumulation. Peak concentrations for $160 \mathrm{mg} /$ day apalutamide at steady-state are $6.0 \mu \mathrm{g} / \mathrm{mL}(12.5 \mu \mathrm{mol} / \mathrm{L})$, relative to peak levels of $16.6 \mu \mathrm{g} / \mathrm{mL}(35.7 \mu \mathrm{mol} / \mathrm{L})$ for $160 \mathrm{mg} /$ day enzalutamide and mean $(R)$-bicalutamide levels of $21.6 \mu \mathrm{g} / \mathrm{mL} \quad(50.2 \mu \mathrm{mol} / \mathrm{L})$ for $150 \mathrm{mg} /$ day bicalutamide. ${ }^{13}$ The mean volume of distribution of apalutamide at steady-state is approximately $276 \mathrm{~L}$. The plasma protein binding of apalutamide is $96 \%$, while that of its major metabolite N-desmethylapalutamide is $95 \%$, both irrespective of concentration. Apalutamide is metabolized in the liver by CYP2C8 and CYP3A4. A major active metabolite, N-desmethylapalutamide, is formed by these enzymes, with similar contribution of each of these enzymes to its formation at steady-state. Following a single oral dose of $200 \mathrm{mg}$ apalutamide, apalutamide represented $45 \%$ and $\mathrm{N}$ desmethylapalutamide $44 \%$ of total area-under-curve levels. The mean elimination half-life of apalutamide at steady-state is 3 to 4 days. ${ }^{14}$ After a single dose of apalutamide, its clearance rate $(\mathrm{CL} / \mathrm{F})$ was $1.3 \mathrm{~L} / \mathrm{h}$, while its clearance rate increased to $2.0 \mathrm{~L} / \mathrm{h}$ at steady-state. This change is considered to be likely due to CYP3A4 autoinduction. Approximately $65 \%$ of apalutamide is excreted in urine $(1.2 \%$ as unchanged apalutamide and $2.7 \%$ as $\mathrm{N}$ desmethylapalutamide) while $24 \%$ is excreted in feces $(1.5 \%$ as unchanged apalutmaide and $2 \%$ as $\mathrm{N}$ desmethylapalutamide).

\section{Side effects}

Hot flushes, joint pain, tiredness, nausea, decreased appetite, weight loss, decreased sexual ability, increased blood pressure, underactive thyroid, unusual weight gain, constipation, seizure, rashes, itching, dizziness.

\section{Therapeutic uses}

Apalutamide is used to treatment with prostate cancer that has not responded to other treatment. This medication belongs to a class of drugs known as anti-androgens (antitestosterone). It works by blocking the effects of testosterone to slow the growth and spread of prostate cancer. It is used mainly in castration resistant nonmetastatic prostate cancer.

\section{Chemistry}

Apalutamide is a structural analogue of enzalutamide and RD-162. ${ }^{15}$ It is a pyridyl variant of RD-162. Enzalutamide and RD-162 were derived from the nonsteroidal androgen RU-59063, which itself was derived from the firstgeneration NSAA nilutamide and by extension from flutamide (NSAA-Nonsteroidal antiandrogenic).

\section{HISTORY}

Apalutamide was originated by the University of California system and was developed primarily by Janssen Research and Development, a division of Johnson and Johnson. It was first described in the literature in a United States patent applicati that was published in November 2007 and in another that was submitted in July 2010. A March 2012 publication described the discovery and development of apalutamide. A phase I clinical trial of apalutamide was completed by March 2012, and the results of this study were published in $2013 .{ }^{16}$ Information on phase III clinical studies was published between 2014 and 2016. Positive results for phase III trials were first described in 2017, and Janssen submitted a New Drug Application for apalutamide to the United States Food and Drug Administration on 11 October 2017. Apalutamide was approved by the Food and Drug Administration in the United States, for the treatment of NM-CRPC on 14 February 2018.

\section{Generic name}

Apalutamide is the generic name of the drug. It is also known by its developmental code names $A R N-509$ and JNJ-56021927.

\section{CONCLUSION}

Aplatumide is a better option for the treatment of castration resistant non-metastatic prostatic carcinoma in adult. It is better option than other Anti-androgen or 5-alpha reductase inhibitors. Aplatumide possess less side effects as comparison to other anti-androgens or 5-alpha reductase inhibitors.

\section{Funding: No funding sources \\ Conflict of interest: None declared \\ Ethical approval: Not required}

\section{REFERENCES}

1. Miller DC, Hafez KS, Stewart A, Montie JE, Wei JT. Prostate carcinoma presentation, diagnosis, and staging: an update form the National Cancer Data Base. Cancer. September 2003;98(6):1169-78.

2. van der Cruijsen-Koeter IW, Vis AN, Roobol MJ, Wildhagen MF, de Koning HJ, van der Kwast TH, et 
al. Comparison of screen detected and clinically diagnosed prostate cancer in the European randomized study of screening for prostate cancer, section rotterdam. Urol. July 2005;174(1):121-5. PMID 15947595.

3. Hankey BF, Feuer EJ, Clegg LX, Hayes RB, Legler JM, Prorok PC, et al. Cancer surveillance series: interpreting trends in prostate cancer- part I: Evidence of the effects of screening in recent prostate cancer incidence, mortality, and survival rates. J Natl Cancer Inst. June 1999;91(12):1017-24.

4. Seruga B, Ocana A, Tannock IF. Drug resistance in metastatic castration-resistant prostate cancer. Nature Reviews Clinical Oncology. January 2011;8(1):12-23.

5. de Bono JS, Oudard S, Ozguroglu M, Hansen S, Machiels JP, Kocak I, et al. Prednisone plus cabazitaxel or mitoxantrone for metastatic castrationresistant prostate cancer progressing after docetaxel treatment: a randomised open-label trial. Lancet. October 2010;376(9747):1147-54.

6. Dellis AE, Papatsoris AG. Apalutamide: The established and emerging roles in the treatment of advanced prostate cancer. Expert Opin Investig Drugs. June 2018. (PMID 29856649).

7. Joseph JD, Lu N, Qian J, Sensintaffar J, Shao G, Brigham D, et al. A clinically relevant androgen receptor mutation confers resistance to secondgeneration antiandrogens enzalutamide and ARN-509. Cancer Discovery. September 2013;3(9):1020-9. (PMID 23779130).

8. Moilanen AM, Riikonen R, Oksala R, Ravanti L, Aho E, Wohlfahrt G, et al. Discovery of ODM-201, a newgeneration androgen receptor inhibitor targeting resistance mechanism to androgen signaling-directed prostate cancer therapies. Scientific Reports. July 2015;5:12007. (PMID 26137992).

9. Ivachtchenko AV, Mitkin OD, Kudan EV, Rjahovsky AA, Vorobiev AA, Trifelenkov AS, et al. Preclinical Development of ONC1-13B, Novel Antiandrogen for Prostate Cancer Treatment. Journal of Cancer. 2014;5(2):133-42. (PMID 24494031).
10. Clegg NJ, Wongvipat J, Joseph JD, Tran C, Ouk S, Dilhas A, et al. ARN-509: a novel antiandrogen for prostate cancer treatment. Cancer Research. March 2012;72(6):1494-503. (PMID 22266222).

11. Pinto Á. Beyond abiraterone: new hormonal therapies for metastatic castration-resistant prostate cancer. Cancer Biology and Therapy. February 2014;15(2):149-55. (PMID 24100689).

12. Cockshott ID. Bicalutamide: clinical pharmacokinetics and metabolism. Clin Pharmacokinet. 2004;43(13):855-78. (PMID 15509184).

13. Rathkopf DE, Morris MJ, Fox JJ, Danila DC, Slovin SF, Hager JH, et al. Phase I study of ARN-509, a novel antiandrogen, in the treatment of castration-resistant prostate cancer. Journal of Clinical Oncology. October 2013;31(28):3525-30. PMC 3782148. (PMID 24002508).

14. Tran C, Ouk S, Clegg NJ, Chen Y, Watson PA, Arora $\mathrm{V}$, et al. Development of a second-generation antiandrogen for treatment of advanced prostate cancer. Science. 2009;324(5928):787-90. PMC 2981508. (PMID 19359544).

15. Rathkopf DE, Morris MJ, Fox JJ, Danila DC, Slovin SF, Hager JH, et al. Phase I study of ARN-509, a novel antiandrogen, in the treatment of castration-resistant prostate cancer. J Clin Oncol. 2013;31(28):3525-30. PMC 3782148. (PMID 24002508).

16. Smith, MR, Liu G, Shreeve SM, Matheny S, Sosa A, Kheoh TS, et al. A randomized double-blind, comparative study of ARN-509 plus androgen deprivation therapy (ADT) versus ADT alone in nonmetastatic castration-resistant prostate cancer (M0-CRPC): The SPARTAN trial; 2014.

Cite this article as: Ranjan RK, Chandra A. Apalutamide: a better option for the treatment of non-metastatic castration resistant prostatic carcinoma. Int J Basic Clin Pharmacol 2018;7:18536. 